\title{
LITIGIOS, HONOR Y DEFENSA
}

\author{
LEDESMA NARVÁEZ, Marianella ${ }^{181}$
}

SUMARIO: 1. Presentación. - 2. El honor como expresión de la dignidad humana. - 3. Elementos configurativos de la atipicidad. - 4. Algunas expresiones legislativas en la experiencia comparada. - 5. Ponderación legal. - 6. Los efectos administrativos de las injurias en el proceso.

\section{Presentación}

Toda confrontación no sólo acoge posiciones divergentes, sino que puede llevar, bajo la euforia del debate, a situaciones emocionales de descontrol que terminen en ofensas y agravios hacia el contrincante. Por supuesto que ello es una conducta impropia y reprochable, pero, es una posibilidad que pueda suceder, sobre todo si se trata de una confrontación judicial, donde las pasiones e indignaciones terminan avasallando la ecuanimidad, no solo de los propios litigantes, sino de apoderados y abogados en la defensa de sus posiciones.

Este trabajo aborda la afectación del honor de las personas involucradas en los litigios judiciales, por su contraparte; quienes bajo el fragor de la discusión procesal son injuriadas y difamadas; sin embargo, a pesar de materializarse la afectación al honor del adversario, no resulta justiciable. En otras palabras no resulta punible, porque a tenor de lo dispuesto en el art. 133 Código Penal, estaríamos ante el supuesto de una conducta atípica, donde no resulta punible la comisión de la injuria y la difamación, siempre y cuando se trate de "ofensas proferidas con ánimo de defensa por los litigantes, apoderados o abogados en sus intervenciones orales o escritas ante el Juez."

Esta eximente de responsabilidad aparecía también regulada en el derogado Código Penal de 1924 bajo el siguiente texto: "Las injurias proferidas por los litigantes, apoderados o defensores en los escritos, discursos o actuaciones producidas antes los tribunales, serán corregidas disciplinariamente, de acuerdo con las leyes de procedimientos. "182

En el Código Penal de 1863 no encontramos un texto que acoja de manera expresa, la atipicidad ni la ausencia de punición de las ofensas en los litigios. ${ }^{183}$

Como se puede advertir de la cita textual del art: 133 del Código Penal vigente, a diferencia del texto del derogado de 1924, la gran justificación para la no punición de las

${ }^{181}$ Jueza supernumeraria de Lima. Bachiller y Doctor en Derecho por la Universidad Nacional Mayor de San Marcos. Profesora en la Facultad de Derecho en la PUCP y U. de Lima en la sección de posgrado de la Universidad de San Martín de Porres, UNMSM y UNIFE. Autora de diversas publicaciones.

${ }^{182}$ Art. 192 Código Penal 1924

${ }^{183}$ Hemos revisado la sección novena del libro II del referido Código de 1863 que comprende los artículos 281 al 292 en el que se aborda los delitos contra el honor y no encontramos referencia alguna en dicho acápite a la atipicidad de las ofensas en litigios. 
ofensas vertidas a través de la injuria y difamación en el litigio, es que éstas sean proferidas por los litigantes, bajo el "ánimo de defensa".

\begin{tabular}{|c|c|}
\hline Código Penal 1924 & Código Penal 1991 \\
\hline $\begin{array}{l}\text { "Las injurias proferidas por los litigantes, } \\
\text { apoderados o defensores en los escritos, } \\
\text { discursos o actuaciones producidas antes los } \\
\text { tribunales, serán } \\
\text { disciplinariamente, de acuerdo con las leyes } \\
\text { de procedimientos." }\end{array}$ & $\begin{array}{l}\text { "no resulta punible la comisión de la } \\
\text { injuria y la difamación, siempre y } \\
\text { cuando se trate de "ofensas proferidas } \\
\text { con ánimo de defensa por los litigantes, } \\
\text { apoderados o abogados en sus } \\
\text { intervenciones orales o escritas ante el } \\
\text { Juez." }\end{array}$ \\
\hline
\end{tabular}

En ese escenario apreciamos del texto legal del art: $133.1 \mathrm{CP}$, la colisión de dos derechos fundamentales, como es, el derecho al honor y el derecho a la defensa, contenidos en el art 2.7 y 139.14 de la Constitución. Como correlato a esa colisión, del propio texto del art: 133.1 CP se puede inferir la prevalencia del derecho de defensa, aún sobre la vulneración al honor, a través de las ofensas y ultrajes vertidos en el proceso judicial. ${ }^{184}$

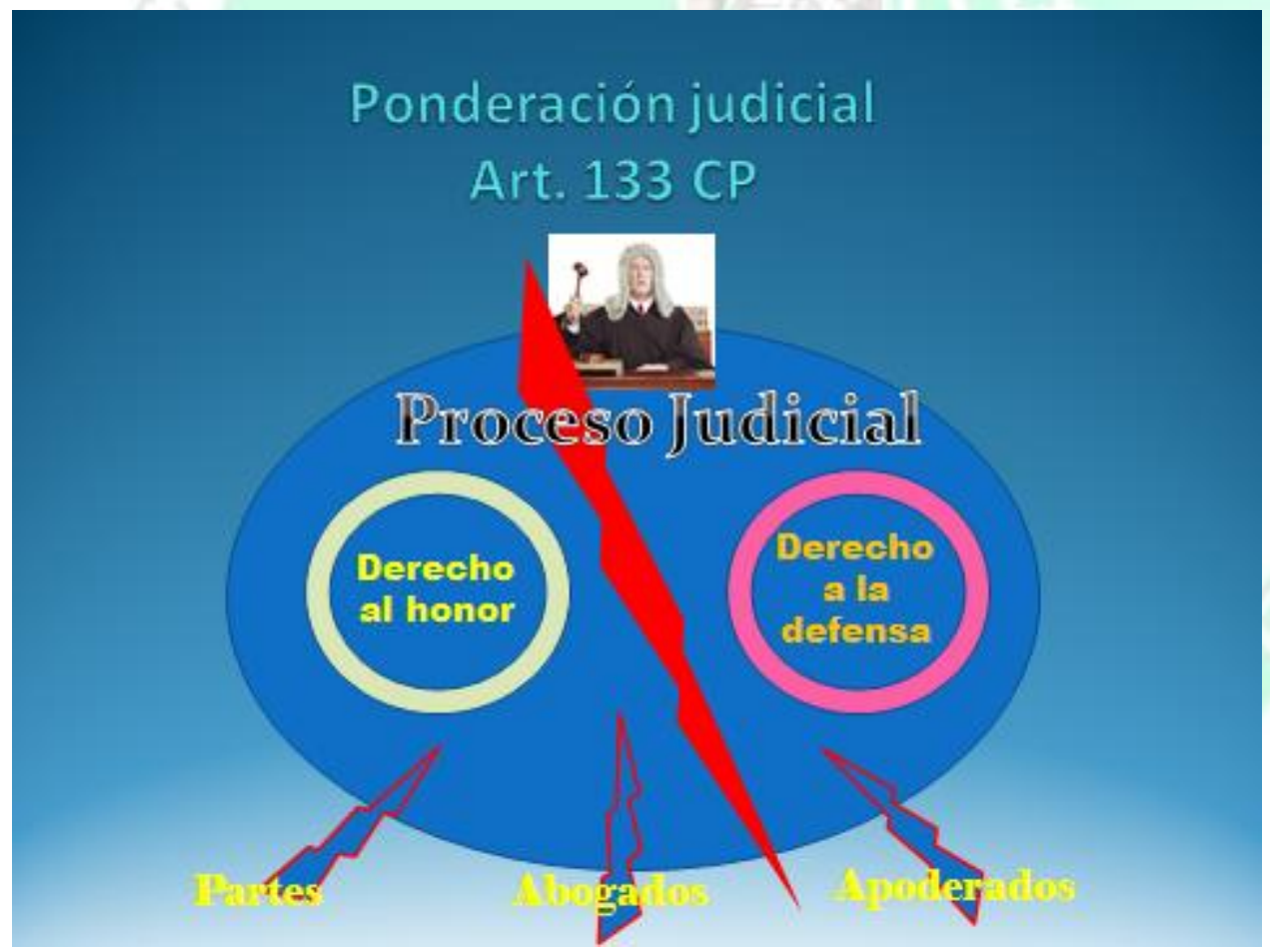

184 Alberto intentando una explicación a este prevalencia dice: "la disposición se fundamenta en el resguardo del principio constitucional de defensa en juicio, pero ningún derecho es absoluto, por ello queda reglamentado que bajo este tipo de injurias quedan sujetas a las correcciones disciplinarias" ALBERTO DONNA, Edgardo, Derecho Penal. Parte especial. t 1, 3ºd, Rubinzal-Culzoni, Buenos Aires, 2008, p. 485 


\section{El honor como expresión de la dignidad humana}

En una sociedad jurídicamente organizada, el derecho a la honra, es considerado como derecho fundamental de la persona humana; de tal manera que el naufragio de los más altos valores morales de nuestro tiempo, los excesos a los atropellos al honor, ponen en serio peligro la vigencia de este derecho, por lo que la protección del mismo, tan propenso a ser atropellado, será la mejor garantía de una convivencia tranquila, digna, libre de zozobras y perturbaciones.

Los supuestos que asume como conducta atípica el art: $133 \mathrm{CP}$ son la injuria ${ }^{185}$ y la difamación ${ }^{186}$. En ambos casos, se busca reprimir la conducta de irreverencia o menosprecio que se realiza contra el honor de la persona (prestigio de la víctima).

Este bien jurídico protegido está reconocido en el artículo 2.7 de la Constitución Política del Estado. En ella se afirma que toda persona tiene derecho al "honor y a la buena reputación". La dignidad humana constituye la esencia misma del honor y determina su contenido, de tal manera que los ataques al honor son ataques inmediatos a la dignidad de la persona. ${ }^{187}$ Hay una correspondencia entre el Código Penal y la Constitución Política del Perú que estima al honor como un derecho fundamental de la persona.

El honor es el derecho que toda persona natural tiene a que se le respete según las cualidades que ella misma se autoasigna. Algunos autores categorizan a la injuria como una ofensa a la "honra" de una persona, o una ofensa al "crédito" de ella, y dicen: como ofensa a la honra, la injuria es una lesión al derecho que tienen las personas a que los terceros respeten las cualidades que se autoasignan. ${ }^{188}$ Como ofensa al crédito la injuria es la lesión al derecho que tiene toda persona a que no se perjudique la opinión que sobre su personalidad tengan o puedan tener los terceros. En esa línea de distinción, Viterbo Arias, ${ }^{189}$ dice que no es lo mismo deshonrar que desacreditar, aun cuando ambas expresiones se usen como sinónimas en el lenguaje corriente. "Deshonrar es quitar la honra, es decir, la reputación que una

${ }^{185}$ El delito de injuria aparece tipificado en el art: $130 \mathrm{CP}$ bajo el siguiente texto: "el que ofende o ultraja a una persona con palabras, gestos o vías de hecho, será reprimido con prestación de servicio comunitario de diez a cuarenta jornadas o con sesenta a noventa días-multa"

186 El delito de difamación aparece tipificado en el art: $132 \mathrm{CP}$ bajo el siguiente texto: "El que, ante varias personas, reunidas o separadas, pero de manera que pueda difundirse la noticia, atribuye a una persona, un hecho, una cualidad o una conducta que pueda perjudicar su honor o reputación, será reprimido con pena privativa de libertad no mayor de dos años y con treinta a ciento veinte días-multa. Si la difamación se refiere al hecho previsto en el artículo 131, la pena será privativa de libertad no menor de uno ni mayor de dos años y con noventa a ciento veinte días-multa. Si el delito se comete por medio del libro, la prensa u otro medio de comunicación social, la pena será privativa de libertad no menor de uno ni mayor de tres años y de ciento veinte a trescientos sesenticinco días-multa."

${ }^{187}$ El Tribunal Constitucional en la sentencia No 2790-2002-AA/TC, del 30.1.2003, ha señalado que se debe proteger a su titular contra el escarnecimiento o la humillación, ante si o ante los demás, e incluso frente al ejercicio arbitrario de las libertades de expresión e información, puesto que la información que se comunique, en ningún caso, puede resultar injuriosa o despectiva.

${ }^{188}$ Citando a Carrara, el autor hace alusión que aunque la honra es un patrimonio del ser humano, no podemos exigirla como un derecho a que nos alaben o rindan tributo de reverencia, pero sí que no nos ultrajen. "no pido a la ley que haga que otro me ame, pero sí que me defienda de su odio". Si bien es cierto que no podemos exigir expresiones físicas de alabanza, loa o admiración de los demás; pero si honra es la estimación que los demás tienen de nuestro propio comportamiento, si podemos exigir respeto, que es el miramiento, consideración o deferencia con que los otros deben apreciar a un prójimo que se lo merece. FERREIRA DELGADO, Francisco José, Derecho Penal Especial, tomo I, Temis SA, Bogotá, 2006, p. 340

${ }^{189}$ Viterbo Arias, José, Exposición comentada y comprada del Código Penal del Perú 1863, t.3, imprenta Torres Aguirre, Unión 150, Lima, 1898, p.196 
persona ha adquirido por sus virtudes y talentos; desacreditar es quitar a alguno la reputación de solvencia, proveniente de su fortuna y de su exactitud en la ejecución de sus contratos. El que dice o escribe de otro que es un ebrio, le deshonra; el que afirma que un comerciante está en falencia, le desacredita"

La finalidad ultrajante se puede canalizar a través de la injuria verbal o escrita, esto significa que se requiere de una acción positiva. En este aspecto, hay algunas opiniones que asumen textualmente la exigencia de la escritura como medio de materializar la injuria, frente a otras posiciones que de manera análoga comprenden bajo el supuesto de la escritura, a todas las injurias que se realicen por medio de las caricaturas, pintura, escultura. Lamentablemente el tipo legal del art: $130 \mathrm{CP}$ asume la oralidad o la escritura, no habiéndose colocado en la posibilidad que existan otros medios que permitan materializar la injuria. En otros textos legales, se contempla que bajo la frase "de cualquier manera" se pueda incorporar, no solo las injurias realizadas por escrito, sino las que se valen de las caricaturas, por decir, para afectar el honor, pero, siempre bajo la restricción que no sean divulgadas.

Tratándose de la injuria verbal, dice Ferrerira, ${ }^{190}$ aunque la ley no lo diga expresamente se necesita la presencia física de la persona deshonrada, es decir, la ofensa se le hace en el mismo ambiente físico del injuriante o a la vista del mismo.

También la ofensa puede manifestarse por medio de gestos o vías de hecho, como cita el propio texto del art: 130 CPC. En este extremo hay quienes hacen una diferenciación entre el gesto y la vía de los hechos. Se asume que el gesto es la expresión que se hace con el rostro, en cambio, las vías de hecho" son las conductas que se exteriorizan por movimientos corporales, distintos a los del rostro. Una bofetada, un escupitajo dirigidos a un persona constituyen también formas de injuriar.

Ferreria al trabajar sobre la composición ontológica de la injuria señala "la injuria es un ultraje a otra persona que necesita expresarse. Comienza o se forma en la conciencia del autor, pero no basta ello, es preciso exteriorizarla y para ello requiere de cualquier expresión corporal que fenomenice ese pensamiento'. La exteriorización no requiere de atributos especiales. Una palabra puede sensibilizar tremendamente o menoscabar la dignidad de otro, al punto de poner en jaque la convivencia entre ambos. Un gesto despectivo o un comportamiento silencioso de repugnancia hacia otro, es suficiente materialidad del pensamiento injurioso por el sujeto activo. ${ }^{191}$

El Acuerdo Plenario No 3-2006/CJ-116 al calificar al honor dice: "es un concepto jurídico ciertamente indeterminado y variable, cuya delimitación depende de las normas valores e ideas sociales vigentes en cada momento histórico, pero que en todo caso, desde una perspectiva objetiva, aluden a la suma de cualidades que se atribuyen a la persona y que son necesarias para el cumplimiento de los roles específicos que se le encomiendan. Desde un sentido subjetivo el honor importa la conciencia y el sentimiento que tiene la persona de su propia valía y prestigio; reputación y la propia estimación son sus dos elementos constitutivos. El Tribunal Constitucional en la sentencia número 0018-1996-AI/TC, del 29.4.1997, hace mención al honor interno y al honor externo, y asume que la injuria, a

\footnotetext{
${ }^{190}$ Ibidem

${ }^{191}$ Ferreira Delgado, Francisco José, Derecho Penal Especial, tomo I, Temis SA, Bogotá, 2006, p. 
diferencia de la difamación y la calumnia, sólo inciden el honor interno, que es muy subjetivo. ${ }^{192}$

En conclusión, podemos afirmar que la injuria es una expresión de afectación al honor de la persona, que daña la imagen y perjudica su reputación como persona. Los hechos expresados pueden contener juicios de valor, ya sean verdaderos o falsos, que atentan contra la persona y terminan dañando su autoestima.

\section{Elementos configurativos de la atipicidad}

Como hemos hecho referencia líneas arriba, en el caso de los delitos de injuria y difamación, la conducta reprochable y penada es aquella del sujeto que ofende o ultraja a una persona ya sea, con palabras, gestos o mueca. Es necesario que se afecte el honor del otro, no basta con su puesta en peligro. Además no se requiere que las ofensas sean verdaderas o falsas, lo que importa es el hecho de afectar el honor de la persona. Todos estos elementos que califican el tipo legal de la injuria, dejan de ser tal, cuando estas son proferidas con ánimo de defensa, por los litigantes, apoderados o abogados, en sus intervenciones orales o escritas ante el Juez.

Esto significa que el escenario en el que se desarrollan estas ofensas es el litigio, en el que el juez tiene una participación natural. Litigar viene del latín litigare que es pelear, discutir con otro sobre algo. Se refiere a las intervenciones en cualquiera de las etapas del proceso, sea oral o por escrito, en el que actúe el abogado y comprende tanto a las partes, como a los apoderados.

a) Un primer elemento a analizar en esta atipicidad es determinar quiénes son los calificados para estar exentos de la punición. Si nos remitimos al propio texto del art: $133 \mathrm{CP}$ considera a los litigantes, apoderados o abogados en sus intervenciones orales o escritas ante el Juez; sin embargo, ello resulta contradictorio si tenemos en cuenta que las partes, abogados y apoderados tienen el deber, según el CPC, de "abstenerse de usar expresiones descomedidas o agraviantes en sus intervenciones". ${ }^{193}$ Aún más, la propia LOJP establece como deber del abogado patrocinante, "actuar con moderación y guardar el debido respeto en sus intervenciones y en los escritos que autorice", "194 "instruir y exhortar a sus clientes para que (...) guarden el debido respeto (...) a todas las personas que intervengan en el proceso.",195

Los litigantes son las partes que intervienen en el juicio y no están comprendidos, el juez, los peritos, los testigos y demás órganos de auxilio judicial; sin embargo, una

${ }^{192}$ La tranquilidad de cada persona y la paz social exigen que la personalidad ajena sean respetadas, de ahí que a toda persona le corresponde un mínimo de respetabilidad y honorabilidad que debe ser protegido por el ordenamiento jurídico; de tal modo que como señala Ferreira, "nadie está excluido de esta tutela, ni siquiera las personas deshonestas o de mala reputación, también estos pueden ser sujetos pasivos de un delito contra el honor siempre que el ataque sea ilegítimo, pues nuestra Constitución, los tratados internacionales de derechos humanos y la ley, presumen que todos los hombres tienen el bien jurídico del honor, por lo cual éste debe ser protegido." FerReIRA Delgado, Francisco José, Derecho Penal Especial, tomo I, Temis SA, Bogotá, 2006, pp. 340

193 Art: 109.3 CPC: Son deberes de las partes, Abogados y apoderados:3. Abstenerse de usar expresiones descomedidas o agraviantes en sus intervenciones.

194 Art: 288.5 LOPJ. Son deberes del abogado patrocinante: 5.- Actuar con moderación y guardar el debido respeto en sus intervenciones y en los escritos que autorice.

${ }^{195}$ Art: 288.7 LOPJ Son deberes del abogado patrocinante: 7.- Instruir y exhortar a sus clientes para que acaten las indicaciones de los Magistrados y guarden el debido respeto a los mismos y a todas las personas que intervengan en el proceso. 
interrogante que surge del texto legal (art: 133.1 CP) es determinar si la ofensa debe afectar estrictamente a las partes involucradas en la litis o ipuede comprender a otras personas estrechamente vinculadas al proceso, como es el caso de los terceros legitimados? Al respecto consideramos que pese a que el tipo legal es bastante restrictivo al considerar a las partes o sus apoderados, debería asumirse bajo ese supuesto a los terceros legitimados, que actúan en el proceso, en la posición de alguna de las partes, sea de manera voluntaria u obligada.

El Código Procesal Civil de 1993 acoge la intervención de terceros, a diferencia de la omisión que contenía el derogado Código de Procedimientos Civiles de 1911, por tanto, cuando entra en vigencia el Código Penal en 1991, la redacción del texto del art: 133.1 no se adecuaba a los alcances del nuevo texto del Código Procesal Civil, sin embargo, consideramos que la jurisprudencia debería ir afinando está participación, pues, tanto el tercero como la parte, asumen una única posición y defensa en el proceso; a diferencia del tercero excluyente principal que se comporta, en estricto, como una parte en el proceso. En este caso, este tercero, a que hace referencia el art: 99 CPC, por más que sea calificado como tercero excluyente, es una parte en el proceso, en la que incorpora -por inserción- una pretensión, generando una acumulación sucesiva de pretensiones.

Todo tercero voluntario, está obligado a adherirse a la parte procesal a la que va a asistir; esto significa que no puede realizar actos de defensa contrarios a la parte que coadyuva $;{ }^{196}$ incluso está legitimado para promover la impugnación, aún contra la voluntad de la parte que coadyuva. ${ }^{197}$ Esto significa, que los alcances del art: $133.1 \mathrm{CP}$ también debe ser extensivo al tercero legitimado que interviene en el proceso.

Hay la posibilidad que en el proceso, en el que interviene el tercero legitimado, este participe en el proceso con mayor ímpetu y dinamismo y pueda generar ofensas al adversario, al fragor del debate y la contienda; las mismas que también deberían ser consideradas atípicas, tan igual, como las que asumen los litigantes, apoderados o abogados en sus intervenciones orales o escritas ante el Juez.

También están comprendidos, como sujetos activos de ésta atipicidad, los abogados, quienes son los defensores que patrocinan a las partes o a sus apoderados en el proceso. Para justificar esta forma de impunidad, se dice que a veces el abogado se ve forzado a contraatacar a su contradictor, con o sin razón de la contraparte. Esto significa que las ofensas se tienen que expresar, en los recintos judiciales ante el juez; no fuera de ellos, ni tampoco tiene que darse frente a personas distintas del profesional que represente a su contraparte.

Estas ofensas se dan con litigantes en cualquiera de las ramas del derecho, ante jueces de diversas materias, sea penal, civil, contencioso administrativo, laboral o de familia. También está comprendida la justicia constitucional, pero, no podría extenderse estos efectos a los tribunales arbitrales, por no desarrollarse ante un escenario estrictamente judicial. ${ }^{198}$

${ }^{196}$ Ver art: 97 CPC

${ }^{197}$ Ver art: 355 CPC

${ }^{198}$ Se asume que los alcances del art: 133.1 no es extensivo para el arbitraje porque el escenario en el que desarrolla el arbitraje no es un escenario judicial, todo lo contrario, es un escenario privado, en el que prima el ejercicio de la autonomía privada, donde la reserva y la privacidad constituyen una de las aristas centrales de esta forma de solucionar los conflictos. La actividad jurisdiccional está premunida de la publicidad como una garantía a los litigantes, a diferencia de la actividad arbitral, donde la privacidad del debate y la solución, es un tema, propio y exclusivo para las partes involucradas en el debate. 
Los jueces, fiscales, procuradores, no están dentro de los alcances del art: $133 \mathrm{CP}$ porque no son litigantes. Si éstos injurian a las partes o a sus abogados, serían responsables por el delito de abuso de autoridad; en sentido contrario, si los litigantes, apoderados o abogados, injurian al juez, se estaría frente al delito de violencia y resistencia a la autoridad, pues, no sería una ofensa a un igual, sino se afectaría la administración pública; de ahí que constituye un deber de las partes, abogados y apoderados, el guardar el debido respeto al Juez, a las partes y a los auxiliares de justicia, tal como lo establece el art: 109.4 CPC. ${ }^{199} \mathrm{De}$ manera especial, la propia LOPJ reafirma como un deber del abogado, el instruir y exhortar a sus para que acaten las indicaciones de los Magistrados y guarden el debido respeto a los mismos" $" 200$

b) El otro elemento a considerar es el modo de comisión con el que se materializa la ofensa. El propio texto del art: $133 \mathrm{CP}$ hace referencia a las intervenciones orales y escritas. ${ }^{201} \mathrm{En}$ el primer caso, tenemos a los alegatos, discursos e informes orales, que son todos, expresiones de palabra vertidas en el proceso. En el caso de los escritos, tenemos a la demanda y su contestación, los alegatos y, en general, toda presentación hecha en el proceso por escrito. ${ }^{202}$

Una interrogante que surge del texto legal de atipicidad, es determinar si la ofensa tiene que tener relación con el objeto del litigio. Si bien el texto legal no hace expresa referencia a ello, consideramos que la atipicidad no está restringida a ultrajes que tengan que ver con el objeto del debate, pues, al fragor de la contienda, se podría ingresar -bajo una mala praxis- a doblegar al adversario afectando su honra, sin que ello sea el contenido o la esencia del objeto del litigio. Es claro que lo que se busca con las ofensas al adversario, es afectar el honor del litigante involucrado en la litis, sin embargo, esa afectación es independiente en sí, al objeto de disputa, el mismo que estará marcado por los hechos que configuran la pretensión. Aún, en el supuesto que el contrincante no tenga asidero en su pretensión, y se desestima ésta posteriormente, nada justifica que se tenga que ultrajar o afectar su honor; son situaciones totalmente diferentes pues una no está en función de la otra, sin embargo esa situación no es una condición de ilicitud penal. En esta línea de coincidencia, encontramos la

${ }^{199}$ Sobre el particular advertimos el siguiente pronunciamiento judicial: Si en la realización de la audiencia tanto el personal del juzgado como el policial fueron objeto de agresión física y verbal, dichos hechos constituyen indicios razonables de la comisión de un delito previsto como violencia y resistencia a la autoridad, que deben ser puestos en conocimiento del Ministerio Público (Exp. No 317-97, Cuarta Sala Civil, Ledesma Narváez, Marianella, Jurisprudencia Actual, Tomo 1, Gaceta Jurídica, p. 506).

${ }^{200}$ Art: 288.7 LOPJ: Son deberes del abogado patrocinante: Instruir y exhortar a sus clientes para que acaten las indicaciones de los Magistrados y guarden el debido respeto a los mismos y a todas las personas que intervengan en el proceso;

Artículo 292.- Sanción disciplinaria a abogados. Los Magistrados sancionan a los abogados que formulen pedidos maliciosos o manifiestamente ilegales, falseen a sabiendas la verdad de los hechos, o no cumplan los deberes indicados en los incisos 1), 2), 3), 5), 7), 9), 11), y 12) del artículo 288. Las sanciones pueden ser de amonestación y multa no menor de una (01) ni mayor de veinte (20) Unidades de Referencia Procesal, así como suspensión en el ejercicio de la profesión hasta por seis meses.

${ }^{201}$ La injuria admite distintos modos de ejecución: puede ser consumada verbalmente o por escrito o mediante actos o hechos que ofendan o ultrajen. Al tenor del tipo que describe el art: 130 y $132 \mathrm{CP}$, no solo las acciones, sino también las conductas negativas, tienen un sentido injurioso cuando son el medio para imputar implícitamente una cualidad, costumbre o conducta deshonrada.

${ }^{202}$ Viterbo, quien se desempeño como juez del crimen en Lima, comentaba precisamente el art:281 del CP 1863 haciendo especial referencia, que carece de importancia para nuestro Foro, la antigua división de las injurias en verbales o de palabra, literales o escritas, pintadas y reales o de hecho; unas y otras se juzgan en la misma forma, y tienen sus respectivas pena según la gravedad del dicho, del concepto escrito o pintado o del hecho injurioso. op. cit. p. 197 
opinión de Alberto Donna, ${ }^{203}$ para quien no es necesario que las injurias tengan una relación estricta con la causa, habida cuenta que la Ley no ha hecho diferencias sobre el punto. Este autor comparte sobre el particular, el siguiente pronunciamiento judicial: "debe arribarse a un temperamento liberatorio en el caso del querellado que en un escrito presentado en una causa ante un juzgado civil, atribuyó al querellante la "condición de homosexual manifiesto" por lo que era "chantajeado por un adolecente con el cual había practicado inclinaciones perversas", etc. Dado que si bien tales injurias no pueden relacionarse para nada con el ejercicio del derecho de defensa, no obstante fueron vertidas en el ámbito de un juicio y no fueron dadas a publicidad." 204

c) El otro elemento a considerar es, el escenario donde se materializa las ofensas. Siempre tiene que operar las ofensas o el ultraje, ante el juez. Debe tratarse de injurias proferidas en escritos, discursos e informes producidos ante los tribunales.

Esto significaría que éstas no deben haber sido proferidas ni divulgadas por sus autores fuera del ámbito judicial. No resulta por tanto aplicable los alcances del art: $133.1 \mathrm{CP}$ si la ofensa proferida no tuvo lugar en el ámbito del proceso, sino ante medios masivos de circulación. En este caso, se descarta el ejercicio del derecho de defensa en juicio; sin embargo, esto es bastante relativo, pues, si se busca preservar que la afectación al honor haya quedado dentro del escenario judicial y no se haya divulgado, este supuesto habría que mirarlo bajo otra arista: cuando ese acto judicial (informe oral) no haya sido trasmitido, a través de medios de comunicación masiva, de tal manera, que el conocimiento del ultraje a la contraparte no haya salido fuera del escenario judicial.

La idea central para este supuesto es la "no publicidad" de la ofensa, para lo cual, solo se tolera que se dé en el escenario judicial, frente al juez y sobre todo, con el fin de la "defensa". Esto último es la gran justificante para la atipicidad de la injuria. A pesar que el texto del art: $133.1 \mathrm{CP}$ no lo diga expresamente, debemos asumir que un requisito para la atipicidad en las injurias, es que sus autores no las hayan dado a la publicidad, que no es lo mismo que no hayan sido de público conocimiento, sobre todo cuando éstas se dan bajo el contexto de una audiencia pública, la misma que es difundida en vivo a través de diversos medios de comunicación masiva. Lo impune es la acción injuriosa, en el contexto del proceso judicial; pero el autor no podrá repetirla a terceros, ajenos al proceso, sin cometer el delito de injuria o difamación, pues el supuesto del art: 133.1 no le alcanza

\section{Algunas experiencias legislativas en la experiencia comparada}

Las injurias al interior del proceso judicial, es un tema permanente en la mayoría de legislaciones hispanas, como mostraremos a continuación.

Sobre las injurias vertidas en juicio, tenemos el texto del Código Penal argentino, cuyo texto pertinente dice:

Art. 115 - Las injurias proferidas por los litigantes, apoderados o defensores, en los escritos, discursos o informes producidos ante los tribunales y no dados a publicidad, quedarán sujetas únicamente a las correcciones disciplinarias correspondientes.

En la legislación penal española encontramos, en el art: 215.2, la siguiente redacción:

${ }^{203}$ Alberto Donna, Edgardo, Derecho Penal. Parte especial. t 1, 3º ed, Rubinzal-Culzoni editores, Buenos Aires, 2008, p. 485

${ }^{204}$ ALBERTO DONNA, op. cit. p. 486 
"Nadie podrá deducir acción de calumnia o injuria vertidas en juicio sin previa licencia del Juez o Tribunal que de él conociere o hubiere conocido."

En el caso colombiano, el art: 228 del Código Penal dice:

Las injurias expresadas por los litigantes, apoderados o defensores en los escritos, discursos o informes producidos ante los tribunales y no dados por sus autores a la publicidad, quedarán sujetas únicamente a las correcciones y acciones disciplinarias correspondientes

El Código Penal del Brasil:Exclusão do crime Art. 142

- Não constituem injúria ou difamação punível: I - a ofensa irrogada em juízo, na discussão da causa, pela parte ou por seu procurador;

En el Código Penal de Chile, en el art. 426 se dice:

La calumnia o injuria causada en juicio se juzgará disciplinariamente, conforme al Código de Procedimientos, por el tribunal que conoce de la causa; salvo el caso en que su gravedad, en concepto del mismo tribunal, diere mérito para proceder criminalmente. En este último caso, no podrá entablarse la acción sino después de terminado el litigio en que se causó la calumnia o injuria.

En el Código Penal Costa Rica, el art. 154 dice:

Las ofensas contenidas en los escritos presentados o en las manifestaciones o discursos hechos por los litigantes, apoderados o defensores ante los Tribunales, y concernientes al objeto del juicio, quedarán sujetas únicamente a las correcciones disciplinarias correspondientes.

En el Código Penal del Ecuador, el art: art. 500 dice:

No darán lugar a la acción de injuria los discursos pronunciados ante los jueces o tribunales, cuando las imputaciones se hubieren hecho en fuerza de la defensa de la causa; como si se ponen tachas a los testigos del adversario y se prueban, para enervar el valor de su testimonio. Sin embargo, los jueces podrán, ya sea de oficio, o a solicitud de parte, mandar que se devuelvan los escritos que contengan injurias de cualquier especie; apercibir a los abogados o a las partes, y aún imponerles multa hasta de dieciséis dólares de los Estados Unidos de Norte América aplicando al efecto las reglas de la Ley Orgánica de la Función Judicial.

Las imputaciones extrañas a la causa dan lugar a la acción correspondiente, sin perjuicio de la multa de que se habla en el inciso anterior.

El Código Penal de Honduras, en el art. 167 se dice:

Nadie podrá deducir acción de calumnia o injuria causadas en juicio sin previa autorización del Juez o Tribunal que de él conociere.

El Código Penal de Nicaragua, en el art. 204 se dice:

No existe el delito de injuria, cuando:

f) Las ofensas contenidas en los escritos presentados o en las manifestaciones o discursos hechos por los litigantes, apoderados o defensores ante los Tribunales, y concernientes al objeto del juicio.

Estas quedarán sujetas únicamente a las sanciones disciplinarias que correspondan.

${ }^{205}$ Se dice que este art: 228 es la transcripción exacta del art: 340 del Còdigo de 1936 
En el Código Penal de Guatemala, en el art: 170, se dice:

Nadie podrá deducir acción de calumnia o injuria causadas en juicio, sin previa autorización del juez o tribunal que de él conociere.

En el Código Penal de la Republica Dominicana, en el art. 374, se dice:

No se considerarán injuriosos ni difamatorios, ni darán lugar a procedimiento alguno, los discursos que se pronuncian en las Cámaras Legislativas, ni los informes, memorias y demás documentos que se impriman por disposición del Congreso, del Poder Ejecutivo o del Judicial. Tampoco dará lugar a ninguna acción, la cuenta fiel que de buena fe den los periódicos de las sesiones públicas del Congreso, ni los escritos producidos o los discursos pronunciados ante los tribunales de justicia; sin embargo, en este último caso pueden los jueces, al conocer del fondo, mandar que se supriman los escritos injuriosos o difamatorios, y aún imponer penas disciplinarias a los abogados que los hubieren producido. Los hechos extraños a la causa, podrán dar lugar a la acción pública o a la civil, cuando los tribunales hubieren reservado ese derecho a las partes o a terceros.

En el Código Penal del Uruguay, en el art. 337, se dice:

La calumnia o injuria causada en juicio, se juzgará disciplinariamente conforme al Código de Procedimiento Civil por el Juez o Tribunal que conozca de la causa, salvo el caso en que su gravedad, en concepto del mismo Juez o Tribunal, diere mérito para proceder criminalmente.

En este último caso, no podrá entablarse la acción sino después de terminado el litigio en que se causó la calumnia o injuria.

\section{Ponderación legal}

Como se puede ya advertir, frente a esta colisión de derechos, el legislador ha optado por hacer prevalecer el derecho a la libertad de defensa, siempre y cuando la comisión de la injuria y la difamación que describe el art: $133.1 \mathrm{CP}$ se den bajo este escenario: a) que la afectación se haya realizado en un proceso judicial, esto implica, frente al Juez y b) que los actores de esa afectación hayan sido las partes, apoderados y abogados. Estos dos supuestos nos llevan a asumir que la parte afectada tiene que ser la contraparte del sujeto agresor y puede recaer esa ofensa no solo en la parte en sí, sino en su apoderado y abogado. Como también ya lo hemos señalado líneas arriba, en el concepto "parte", no solo se comprende al sujeto en sí, sino que puede estar integrada por terceros legitimados que asumen o se adhieren a la posición de una de las partes en el proceso, como es el caso del tercero coadyuvante o de la intervención litisconsorcial.

El texto del art: 133.1 CP es todavía más flexible para esta interpretación, pues, no hace expresa referencia al concepto de "parte", sino a la categoría de "litigantes" sin precisar si tienen la posición de partes o terceros, pues, lo fundamental es que estén en el proceso bajo una situación de adversarios, bajo posiciones enfrentadas, esto es, en controversia.

El legislador ha hecho una ponderación legal y ha privilegiado la libertad de la defensa, siempre que operen los tres siguientes supuestos: a) sea realizada por litigantes, abogados y apoderados; b) sea realizada a través de intervenciones escritas u orales ante el juez y c) las ofensas sean realizadas bajo el animus de la defensa. La suma de ellas, nos lleva al resultado final de las conductas atípicas en el caso de la afectación al honor de dichos sujetos. 
El elemento ponderativo que corresponde está vinculado al principio de proporcionalidad, en cuya virtud el análisis está centrado en determinar el interés público de las frases cuestionadas. Estas deben desbordar la esfera privada de las personas, única posibilidad que permitiría advertir la necesidad y relevancia del interés público en las frases vertidas.

Otro referente que concurre en la ponderación podría ser que la punición penal como la última ratio para sancionar conductas que provocan un mayor daño a bienes jurídicos. Evidentemente, que la presencia o no de expresiones indudablemente ultrajantes u ofensivas, que denotan que están desprovistas de fundamento y o formuladas de mala fe, sin relación con las ideas u opiniones que se expongan, por más que sean expresiones ajenas, duras o desabridas y que puedan molestar, inquietar o disgustar a quien se dirige no son justificantes suficientes para penalizar esa conducta, en un escenario de defensa.

Lo que hemos puesto en evidencia en este trabajo es la confrontación entre dos derechos constitucionales: defensa y honor, concluyendo el legislador en la ponderación interna que la defensa prevalece frente a la ofensa; pero, cuando estas ofensas son proferidas bajo la divulgación de un acto procesal, con la intervención de medios de comunicación masiva, por ejemplo, medios de prensa que van trasmitiendo las incidencias -en vivo- del debate, la afectación es mayor, pues, ya no solo se configuraría el ultraje a la persona sino que esta se vería agravada bajo la figura de la divulgación, tipificando la difamación ${ }^{206}$; sin embargo debemos precisar que la atipicidad en los casos de afectación al honor solo comprende a la injuria y difamación, mas no se extiende a la calumnia, entendida ésta como el atribuir falsamente a otro un delito. Se estaría ante otra dimensión de la afectación, que no comprende los supuestos de atipicidad.

Algunas opiniones atribuyen a esa ponderación legal, la categoría de una compensación de injurias, situación que no sería aplicable en el caso del art: $133.1 \mathrm{CP}$, sino al caso de las injurias reciprocas, contenidas en el art: $137 \mathrm{CP}$, que dice: "En el caso de injurias recíprocas proferidas en el calor de un altercado, el juez podrá, según las circunstancias, declarar exentas de pena a las partes o a una de ellas. No es punible la injuria verbal provocada por ofensas personales." ${ }^{207}$ Según Manzini y Núñez las injurias recíprocas que se dan entre dos personas tienen una relación de causa efecto, ya que la segunda injuria (injuriarespuesta) debe tener su génesis en la primera (injuria-provocación); en ese sentido una injuria verbal podría ser contestada con otra injuria verbal o con un gesto. Estas injurias recíprocas podemos catalogarlas como expresión de autotutela, frente al ejercicio de una legítima defensa.

Esta última situación, en opinión de Alcalá Zamora y Castillo, ${ }^{208}$ provoca la homologación procesal de autodefensa, representada por una especie de duelo verbal de imprecaciones y replicas que es abordado bajo la denominación de compensación judicial de

${ }^{206}$ En este sentido léase el art: 228 Código Penal Colombiano que pone especial énfasis en que las injurias expresadas por los litigantes, apoderados o defensores, ante los tribunales, no deben ser dados por sus autores a la publicidad, sin perjuicio de ello, no es que corre la impunidad, sino que se sujetan únicamente a las correcciones y sanciones disciplinarias correspondientes. Esta redacción es más precisa frente al texto de nuestro Código Penal (133.1) que se limita a declarar la atipicidad, mas no hace especial énfasis en la prohibición de la publicidad por sus autores y la sanción administrativa.

${ }^{207}$ Nótese que el texto del art: 137 CP no hace referencia a la difamación o la calumnia, sino a la injuria recíproca.

208 AlCALA-ZAMORA Y CASTILlo, Niceto, Proceso, autocomposición y autodefensa, textos universitarios UNAM, $2^{\circ}$ ed, México, 1970, p.184 
las injurias recíprocas; sin embargo, hay que precisar que algunos autores califican como "compensación recíproca de injurias" al texto contenido en el art: $137 \mathrm{CP}$, pero para otras opiniones, ello no es correcto, pues, la compensación no requiere de reciprocidad (injurias mutuas). La doctrina señala la concurrencia de los siguientes requisitos: $a$ ) Se necesita cierta proporción entre las respectivas injurias; $b$ ) Cuando la injuria es más grave solo debe valer como atenuante, pues en este caso no cabe compensación; c) Hay que probar la compensación de injurias; y $d$ ) se presume que hay renuncia a la acción penal; y, e) quien devuelve una injuria bajo la presión de un ultraje recibido no piensa en ofender a otro, sino que da lugar a una exclusión producida por el sentimiento de la propia ofensa. ${ }^{209}$

En conclusión, el contenido del art: 133.1 CP se fundamenta en la libertad de la defensa en juicio, la misma que podría desbordar y avasallar otros derechos, como el honor de las personas.

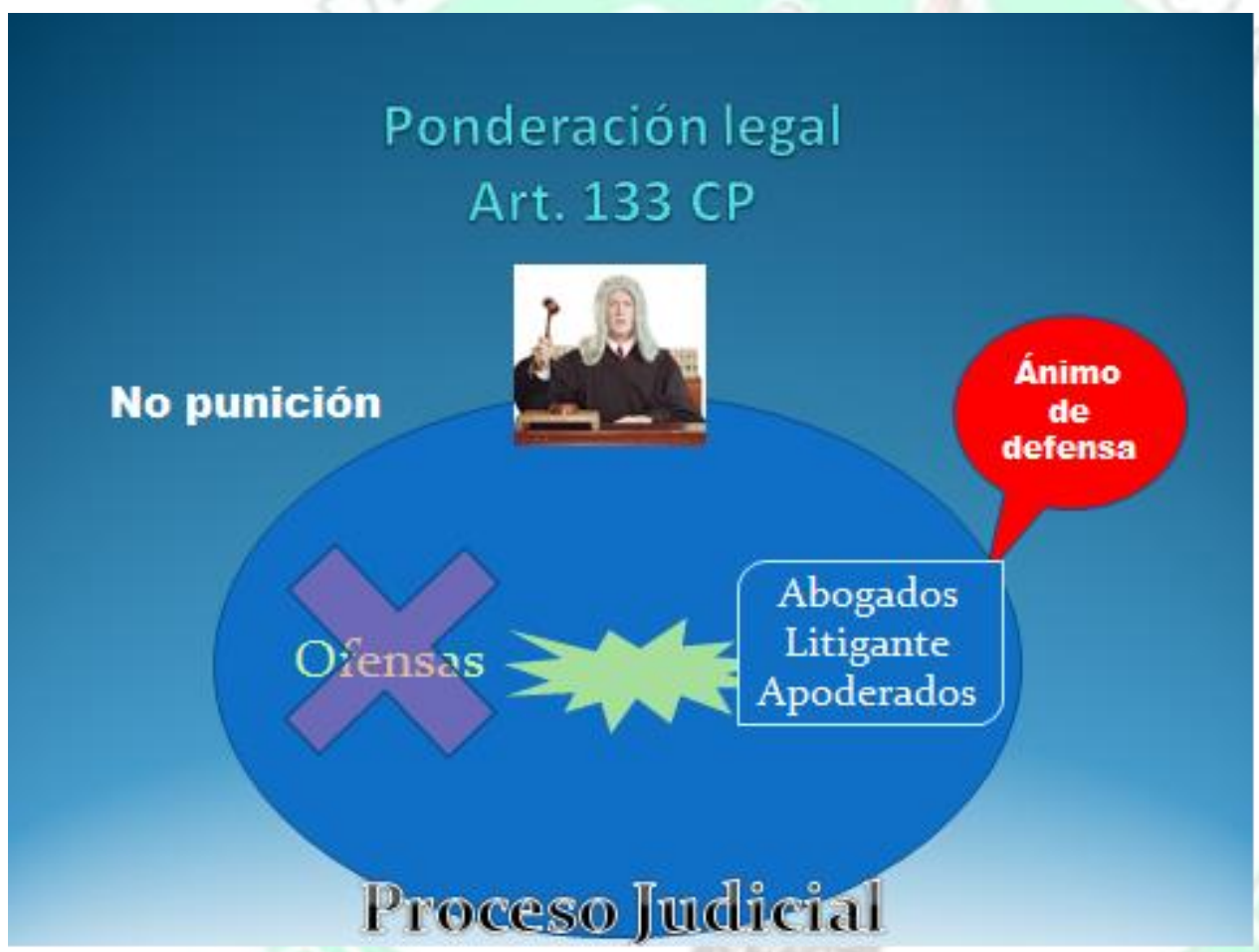

\section{Los efectos administrativos de las injurias en el proceso}

Hemos revisado los antecedentes de la atipicidad de las injurias en los litigios, en sede nacional, y hemos advertido que tanto el Código vigente como el Código de 1924 no consideraban a estas injurias punibles. De manera expresa el Código de 1924 señalaba que esas injurias deberían ser "corregidas" disciplinariamente, a diferencia del texto del Código

209 "Nuñez, afirma que debe hacer cierta compensación entre las injurias, aspecto que es criticado por Aguirre Obarrio, al decir que los delitos no pueden compensarse como las deudas o créditos. Y afirma que la razón del legislador está en que no conviene aplicar sanción cuando las partes se han reprimido mutualmente." Citado por Alberto Donna, op. cit. p. 488 
Penal vigente que no regula nada al respecto; sin embargo, si nos remitimos a las normas del Código Procesal Civil y de la Ley Orgánica del Poder Judicial si vamos a encontrar supuestos de "sanción pecuniaria" por la comisión de esas inconductas.

Esto difiere del concepto de "correcciones disciplinarias" que asumía el derogado Código de 1924, a diferencia del Código vigente, pues, no solo se trataba de medidas que busquen reformar y encausar conductas de los litigantes a futuro, sino de reprochar la realización de actos que afectan la dignidad de los litigantes, sancionándolos pecuniariamente.

Los litigantes están exonerados de proceso penal por injurias y difamación, proveniente de los apoderados u abogados de la contraparte, a tenor del texto del art: $133 \mathrm{CP}$, pero esa exoneración no se extiende a la comisión del delito de calumnia, la misma que sería reprochable penalmente.

En el caso del afectado por injuria, éste puede aspirar a una sanción disciplinaria. El art 50.3 CPC, fija como deber de las partes, abogados y apoderados, "abstenerse de usar expresiones descomedidas o agraviantes en sus intervenciones," El juez ejerce sus facultades disciplinarias en este caso, ordenando que se suprima la frase o palabra expresada o redactada en términos ofensivos o vejatorios.$^{210}$ Además el juez está facultado para aplicar las sanciones disciplinarias que el CPC establece como las sanciones pecuniarias que fija el art: $53 \mathrm{CPC}^{211}$

El respeto al honor del adversario, es un deber contenido no sólo en las reglas del proceso civil, sino que también la Ley Orgánica del Poder Judicial pone especial énfasis, cuando fija como deberes del abogado patrocinante: "actuar con moderación y guardar el debido respeto en sus intervenciones y en los escritos que autorice,212 Esto significa que los jueces están facultados para sancionar a los abogados cuando se aparten del cumplimiento de esos deberes. El art: 292 LOPJ así lo establece y fija las sanciones, las mismas que pueden ser de amonestación y multa no menor de una (01) ni mayor de veinte (20) Unidades de Referencia Procesal, así como suspensión en el ejercicio de la profesión hasta por seis meses. $^{213}$

Como se podrá advertir de la legislación citada, las leyes procesales y de organización judicial contienen disposiciones de carácter disciplinario. Estas normas tienen como contenido axiológico el orden. Se instituyen para asegurar el normal desenvolvimiento de la

${ }^{210}$ Ver art: 52.1 CPC: A fin de conservar una conducta procesal correspondiente a la importancia y respeto de la actividad judicial, los jueces deben: 1.Ordenar que se suprima la frase o palabra expresada o redactada en términos ofensivos o vejatorios.

${ }^{211}$ Artículo 53.- En atención al fin promovido y buscado en el Artículo 52, el Juez puede:

1. Imponer multa compulsiva y progresiva destinada a que la parte o quien corresponda, cumpla sus mandatos con arreglo al contenido de su decisión. La multa es establecida discrecionalmente por el Juez dentro de los límites que fija este Código, pudiendo reajustarla o dejarla sin efecto si considera que la desobediencia ha tenido o tiene justificación; y

2. Disponer la detención hasta por veinticuatro horas de quien resiste su mandato sin justificación, produciendo agravio a la parte o a la majestad del servicio de justicia. En atención a la importancia y urgencia de su mandato, el Juez decidirá la aplicación sucesiva, individual o conjunta de las sanciones reguladas en este Artículo.

${ }^{212}$ Art: 288.5 LOPJ

${ }^{213}$ El citado art: 292 LOPJ dice además: Las resoluciones que impongan sanción de multa superior a dos (02) Unidades de Referencia Procesal o de suspensión, son apelables en efecto suspensivo, formándose el cuaderno respectivo. Las demás sanciones son apelables sin efecto suspensivo. Las sanciones son comunicadas a la Presidencia de la Corte Superior y al Colegio de Abogados del Distrito Judicial respectivo. 
función jurisdiccional. Una de las facultades disciplinarias que recoge el Código Procesal, es la posibilidad de suprimir la frase o palabra expresada o redactada en términos ofensivos o vejatorios. La norma parte del supuesto que las partes deben de abstenerse de usar expresiones descomedidas o agraviantes en sus intervenciones y deben guardar el debido respecto al juez, a las partes y a los auxiliares de justicia (ver los incisos 3 y 4 del artículo 109 del CPC).

Como se ha señalado cuando se vulnere estos deberes el juez no sólo está facultado para testar las expresiones agraviantes o descomedidas, sino imponer sanciones pecuniarias, como parte de la sanción administrativa. Nótese que por más que dichas intervenciones puedan contener términos ofensivos o vejatorios, ello no configura la comisión de un ilícito penal, a pesar de lo delictivo del acto.

El derecho administrativo disciplinario es sancionador y presupone jerarquía y subordinación. Quien ejerce potestad jerárquica, impone formas de conductas previstas en la ley, para asegurar el cumplimiento de la misma. El que está sometido a una subordinación debe obedecer y ajustar su conducta a lo preceptuado; pero dicha disciplina tiene que estar subordinada a un referente legal y que en estos casos serían las contempladas en el Código Procesal Civil y la Ley Orgánica del Poder Judicial. ${ }^{214}$

\section{Conclusiones}

1.La atipicidad a los actos de injuria y difamación, a que refiere el art: 133.1 del Código Penal, es el resultado de la ponderación legal que ha hecho el legislador, entre defensa y honor, para hacer prevalecer la libertad de la defensa en juicio.

2. El elemento ponderativo está vinculado al principio de proporcionalidad, cuyo análisis estará centrado en determinar el interés público de las frases cuestionadas. Otro referente es la punición penal como la última ratio para sancionar conductas que provocan un mayor daño a bienes jurídicos.

3. La impunidad sólo alcanza a las ofensas inferidas en juicio y no dadas a publicidad, pero, éstas sí tienen un tratamiento administrativo judicial, porque son sancionadas pecuniariamente, como el pago de multas; sin perjuicio que el juez ordene se teste las frases o palabras ofensivas, pero, de ninguna manera implica la comisión de un delito de difamación o injuria.

4.El tratamiento que el Código Penal ha dado a las ofensas proferidas en los litigios, no es tema de compensación procesal que conlleve a la homologación procesal, pues, ella es aplicable al caso de las injurias mutuas. Se trata de un tema de ponderación legal, cuyo resultado llevará a la atipicidad de las ofensas, siempre y cuando estas se hayan proferido bajo el animus de la defensa en un proceso judicial, al margen de la naturaleza del conflicto en debate.

${ }^{214}$ Sobre el particular advertimos el siguiente pronunciamiento judicial: "Se les debe aplicar sanción al litigante y a su abogado que faltan a la verdad y no guardan respeto y moderación hacia la autoridad judicial (Exp. No 698-95, Segunda Sala Civil, Ledesma Narváez, Marianella, Ejecutorias, Tomo 2, Cuzco, 1995, pp. 232-233). 